\title{
Minimum friction losses in wind turbine gearboxes
}

\author{
José I. Pedrero ${ }^{1}$ (D) - Débora Martínez-López ${ }^{1}$ José Calvo-Irisarri² Miguel Pleguezuelos $^{1}$ (D) \\ Miryam B. Sánchez ${ }^{1}$ (D) A Alfredo Fernández-Sisón²
}

Received: 24 March 2021 / Accepted: 25 July 2021 / Published online: 15 September 2021

(c) The Author(s) 2021

\begin{abstract}
Improving the mechanical efficiency is not the most important objective in the design of wind turbine gearboxes since the available wind energy is abundant and costless. The most important criteria for dimensioning the gearbox are the fatigue strength—bending and pitting-, noise emission, vibrations, and maintenance requirements. Nevertheless, mechanical losses increase the lubricant temperature and induce thermal stresses, which increases wear and cracking risk. This means that friction losses should be reduced as much as possible, but always regarding the contact and tooth-root stress levels, as well as the other operating parameters which should be kept for ensuring the required operating conditions.

In this paper, a study on the variation of the friction losses with the tooth shift coefficients is presented. All the other geometrical parameters - number of teeth, tooth height, pressure angle, helix angle, face width, and center distance-are unalterable, since all of them have been chosen according to more important design requirements. In addition, to keep the contact and tooth-root stress levels, the shift coefficients of the sun, planets and ring are calculated in such a way that the transverse contact ratios are kept, and therefore the critical load points for bending and pitting are also unchanged. The radial clearance is also kept in order to allow the proper evacuation of the lubricant. Finally, all the geometrical constraints (undercut, pointing, root interference, secondary interference, backlash) are also imposed. With all these restrictions, the optimal shift coefficients for all the gears are calculated to minimize the friction losses.
\end{abstract}

\section{Minimale Reibungsverluste in Getrieben von Windkraftanlagen}

\section{Zusammenfassung}

Die Verbesserung des mechanischen Wirkungsgrads ist nicht das wichtigste Ziel bei der Konstruktion von Getrieben für Windkraftanlagen, da die verfügbare Windenergie im Überfluss vorhanden ist und nichts kostet. Andere Kriterien wie die Lebensdauer (Verbiegungen und Lochfraß), Geräuschemissionen, Vibrationen und Wartungsanforderungen sind für die Konzipierung des Getriebes wichtiger. Mechanische Verluste erhöhen jedoch die Temperatur des Schmierstoffs und führen zu thermischen Spannungen, was die Gefahr von Verschleiß und Rissbildungen erhöht. Das bedeutet, dass die Reibungsverluste so weit wie möglich reduziert werden sollten, jedoch immer unter Berücksichtigung der kritischen Restriktionen wie der Kontakt- und Zahnfußbeanspruchung und anderer Betriebsparameter, die die erforderlichen Betriebsbedingungen sicherstellen.

Availability of data and material Not applicable.

Code availability Not applicable.

José I. Pedrero

jpedrero@ind.uned.es

Débora Martínez-López

dmartinez980@alumno.uned.es

José Calvo-Irisarri

JOSE.CALVO@siemensgamesa.com

Miguel Pleguezuelos

mpleguezuelos@ind.uned.es
Miryam B. Sánchez

msanchez@ind.uned.es

Alfredo Fernández-Sisón

ALFREDO.FERNANDEZ.S@siemensgamesa.com

1 Departamento de Mecánica, UNED, Juan del Rosal 12, 28040 Madrid, Spain

2 Gamesa Energy Transmission-SGRE ON, Zamudio, Vizcaya, Spain 
In diesem Text wird eine Studie über die Variation der Reibungsverluste mit den Zahnverschiebungskoeffizienten vorgestellt. Um die entworfenen Betriebsbedingungen beizubehalten, sind alle anderen geometrischen Parameter (Anzahl Zähne, Eingriffswinkel, Schrägungswinkel, Zahnbreite und Achsabstand) unveränderlich, wobei davon ausgegangen wird, dass all diese Parameter entsprechend den wichtigeren Konstruktionsanforderungen gewählt wurden. Um die Kontakt- und Zahnfußspannungen beizubehalten, werden die Ausgangsradien so berechnet, dass die transversalen Kontaktverhältnisse beibehalten werden und somit die kritischen Belastungspunkte für ein Verbiegen und für Lochfraß unverändert bleiben. Bei der Berechnung der Zahnverschiebungskoeffizienten wurden zwei Kriterien berücksichtigt: die Beibehaltung der Radialluft, um eine ordnungsgemäße Entleerung des Schmiermittels zu ermöglichen, und die Beibehaltung der Zahnhöhe, um Standardabmessungen zu gewährleisten. Mit all diesen Einschränkungen werden die optimalen Schaltkoeffizienten für alle Zahnräder berechnet, um die Reibungsverluste zu minimieren.

\section{Introduction}

High efficiencies are not essential in wind turbine gearboxes. In fact, the turbine fuel-the wind energy—is abundant and costless. However, several strict requirements are imposed by the specific operating conditions:

- Very high power and gear ratio, which means high torques and stress levels.

- Difficult access installations, which hinders maintenance tasks and imposes wider safety margins.

- Severe environmental and structural requirements related to noise and vibration levels.

From these requirements, the final design will ensure high levels of strength, reliability, and durability [1], while the mechanical efficiency will be a less important result of the chosen solution. A good obtained efficiency will mean less energy extracted from the wind, and a bad efficiency, more energy extracted from the wind. But in both cases the electric output power will be the expected one. Nonetheless, on a second level of importance, the power losses will increase the lubricant temperature and induce thermal stresses on the tooth surface. The high lubricant temperature may result in several failure modes as wear, scuffing and pitting [2]. Thermal stresses may produce cracking failures [3]. In addition, limitations on inlet temperature (usually $65-70{ }^{\circ} \mathrm{C}$ ) may result in a larger cooling system. To avoid these problems, the mechanical power losses, and specifically the friction losses, should be reduced as much as possible, but in such a manner that the safety, reliability, and durability levels were not decreased.

Some studies on the power loss can be found in literature relating to cylindric parallel-axis gears [4-10]. But due to the high gear ratio and high power-density required by the wind turbine, gearboxes based on planetary gear sets are commonly used [11]. Literature on power loss of planetary gears are scarcer, although it has been of interest to some researchers [11-15]. The work of Nutakor et al. [11] is specifically focused on the power loss modelling of windturbines two stage planetary gear sets, and includes a parametric study on the influence of various design parameters, as the carriers speed, face width, module, pressure angle, and helix angle. Although it may be interesting to know how these parameters affect the power losses, all of them will also have heavy influence on more important design parameters, as the teeth dimensions and transmitted loads, and consequently on the stress levels and load carrying capacities.

But owing to the specific operating conditions of the wind turbine gearboxes it is not appropriate to improve the mechanical efficiency at expense of worsen the teeth strengths or load carrying capacities. In consequence, results of the mentioned studies [11-15] are not entirely applicable to win turbines. In this paper, a new optimization method of the mechanical losses in wind turbine gearboxes, regarding the design parameters to ensure the desired operating conditions, is presented. All the dimensions of each gear will be unalterable, except the output radii: the number of teeth, pressure angle, helix angle, face width, and center distance. The output radii will be chosen in such a manner that the transverse contact ratios do not change, thereby the critical load points for bending and pitting will not change their locations and therefore the stresses levels and the carrying capacities will be kept. This results in a single degree of freedom for the analysis, for example, the output radius of the sun. The output radius of the planet will be given by one of the sun and the transverse contact ratio of the sunplanet pair, while the output radius of the ring will be given by one of the planet and the transverse contact ratio of the planet-ring pair.

To adopt a specific value of the output radius a suitable rack shift coefficient will be chosen. Two different possibilities will be considered for the sun-planet pair: choosing the rack shift coefficient to keep the tooth height or to keep the radial clearance, to ensure proper evacuation of the lubricant. The rack shift coefficient of the ring will always be calculated to keep the tooth height. The tooth height or the radial clearance of the initial design will be kept, regardless whether they are the nominal ones or not. Obviously, geometrical constraints (undercut, pointing, root interference, secondary interference, backlash) are regarded in the analysis. For this study, the load distribution model developed by 


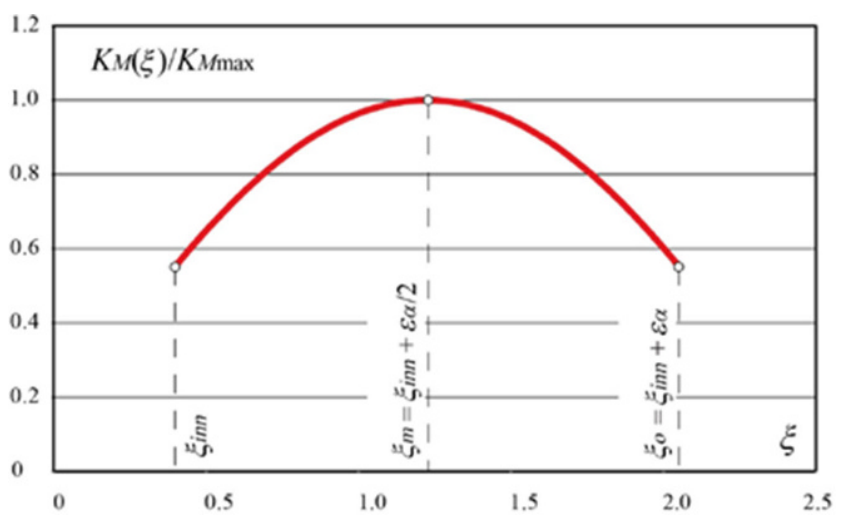

Fig. 1 Single meshing stiffness along the interval of contact

the authors for external [16-18] and internal $[19,20]$ gear pairs will be used. The friction power losses have been calculated as presented in [11]. Only the sliding friction losses has been considered as they have the strongest influence on the surfaces heating. Curves of friction power losses for a specific multi-MW wind turbine gearbox of SiemensGamesa, presently in the design stage, are also presented.

\section{Models for load distribution and friction power losses}

The fraction of the load transmitted by a given spur pair can be expressed as [16-20]:

$R_{i}(\xi)=\frac{F_{i}(\xi)}{F_{T}}=\frac{K_{M i}(\xi)}{\sum_{j} K_{M j}(\xi)}$

where $R$ is the load sharing ratio, $F_{i}$ the load at spur pair $i, F_{T}$ the total load, $K_{M}$ the single meshing stiffness, $\xi$ the contact point parameter and the sum is extended to all the tooth pairs in simultaneous contact. The contact point parameter $\xi$ describes the contact point at the pressure line and is defined as follows:

$\xi=\frac{z_{1}}{2 \pi} \sqrt{\frac{r_{c 1}^{2}}{r_{b 1}^{2}}-1}$

in which $z$ is the tooth number, $r_{C}$ the contact point radius, $r_{b}$ the base radius, and subscript 1 denotes the pinion. Inside the contact interval $\xi_{\text {inn }} \leq \xi \leq \xi_{\text {o }}$, the single meshing stiffness can be approximated by the equation [16-20]:

$K_{M}(\xi)=K_{M \max } \cos \left(b_{0}\left(\xi-\xi_{m}\right)\right)$ with:

$$
\begin{aligned}
b_{0} & =\left[\frac{1}{2}\left(\kappa_{1}+\frac{\varepsilon_{\alpha}}{2}\right)^{2}-\kappa_{2}\right]^{-1 / 2} \\
\xi_{m} & =\xi_{\text {inn }}+\frac{\varepsilon_{\alpha}}{2}
\end{aligned}
$$

where $\varepsilon_{\alpha}$ is the transverse contact ratio, $\xi_{i n n}, \xi_{o}$, and $\xi_{m}$ the contact point parameters corresponding to the inner, the outer, and the midpoint of the interval of contact, respectively, and:

$\kappa_{1}=1.11$ and $\kappa_{2}=1.17$ for external gears

$\kappa_{1}=1.00$ and $\kappa_{2}=1.00$ forinternal gears

The amplitude $K_{M \max }$ is not necessary to know the load sharing, as seen in Eq. 1. The typical shape of the meshing stiffness curve can be observed in Fig. 1.

According to Eq. 2, the difference between the contact point parameters corresponding to two consecutive pairs in contact will be equal to 1 , while the difference between the parameters corresponding to inner and outer points of contact will be equal to the transverse contact ratio, in consequence:

$\xi_{i+1}=\xi_{i}+1 \quad \Rightarrow \quad \xi_{i+j}=\xi_{i}+j$

$\xi_{0}=\xi_{\text {inn }}+\varepsilon_{\alpha} \Rightarrow \xi_{m}=\xi_{\text {inn }}+\frac{\varepsilon_{\alpha}}{2}$

Accordingly, Eq. 1 can also be expressed as follows:

$F(\xi)=\frac{K_{M}(\xi)}{\sum_{j} K_{M}(\xi+j)} F_{T}$

in which $K_{M}(\xi)=0$ outside the contact interval $\left(\xi<\xi_{\text {inn }}\right.$ or $\xi>\xi_{o}$ ). To generalize this equation for helical gears, the single meshing stiffness can be expressed as follows:

$$
\begin{aligned}
K_{M}(\xi) & =K_{M \max } \cos \left(b_{0}\left(\xi-\xi_{m}\right)\right) \\
& =K_{M \max }^{\prime} b \cos \left(b_{0}\left(\xi-\xi_{m}\right)\right)
\end{aligned}
$$

where $b$ denotes the face width. Each transverse section of the helical tooth can be considered as a spur gear with small face width $\mathrm{d} b$, therefore Eq. 7 can be written as follows:

$$
\begin{aligned}
\mathrm{d} F\left(\xi, \xi_{0}\right) & =\frac{K^{\prime} M \max \cos \left(b_{0}\left(\xi-\xi_{m}\right)\right) \mathrm{d} b}{\int_{l_{c}\left(\xi_{0}\right)} K^{\prime} M_{\max } \cos \left(b_{0}\left(\xi-\xi_{m}\right)\right) \mathrm{d} b} F_{T} \\
& =\frac{\cos \left(b_{0}\left(\xi-\xi_{m}\right)\right) \mathrm{d} b}{\int_{l_{c}\left(\xi_{0}\right)} \cos \left(b_{0}\left(\xi-\xi_{m}\right)\right) \mathrm{d} b} F_{T}
\end{aligned}
$$


a

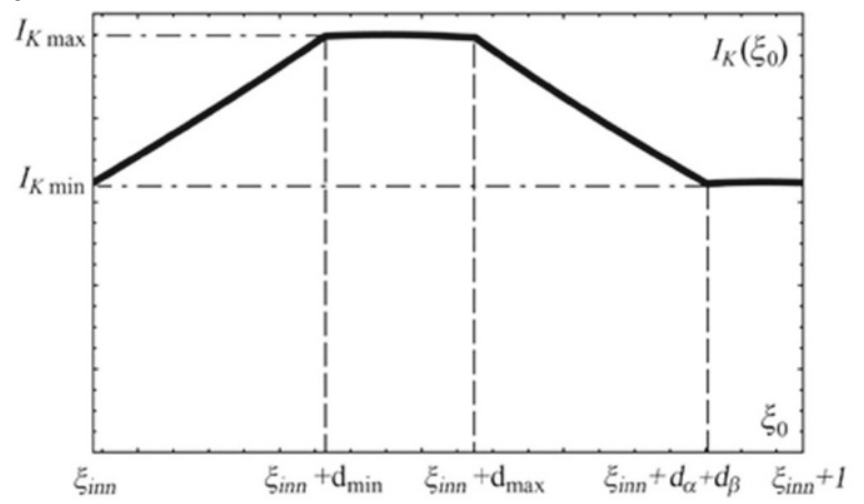

Fig. 2 Typical aspect of function $I_{K}\left(\xi_{0}\right)$ for $d_{\alpha}+d_{\beta}<1(\mathbf{a})$, and $d_{\alpha}+d_{\beta}>1(\mathbf{b})$

where $\xi_{0}$ is the contact point parameter of the reference transverse section and the integral is extended to the entire line of contact $l_{c}$, which is obviously a function of $\xi_{0}$. (Do not confuse $\xi_{0}$ with $\xi_{o}$, the outer point of contact parameter). It can be easily proved that, for the points of the line of contact, it is verified:

$\mathrm{d} \xi=\frac{\varepsilon \beta}{b} \mathrm{~d} b$

where $\varepsilon_{\beta}$ is the axial contact ratio and $\beta_{b}$ the base helix angle. Accordingly, Eq. 9 can be written as:

$$
\begin{aligned}
\mathrm{d} F\left(\xi, \xi_{0}\right) & =\frac{\cos \left(b_{0}\left(\xi-\xi_{m}\right)\right) \mathrm{d} \xi}{\int_{l_{c}\left(\xi_{0}\right)} \cos \left(b_{0}\left(\xi-\xi_{m}\right)\right) \mathrm{d} \xi} F_{T} \\
& =F_{T} \frac{\cos \left(b_{0}\left(\xi-\xi_{m}\right)\right)}{I_{K}\left(\xi_{0}\right)} \mathrm{d} \xi
\end{aligned}
$$

The integral $I_{K}$ can be obtained from [16]:

$$
\begin{aligned}
I_{K}\left(\xi_{0}\right)= & \frac{1}{b_{0}} \sum_{j=-E_{\alpha}}^{E_{\gamma}}\left(\sin b_{0}\left(\xi_{j-\text { high }}-\xi_{m}\right)\right. \\
- & \left.\sin b_{0}\left(\xi_{j \text {-low }}-\xi_{m}\right)\right) \\
\xi_{j-\text { high }}= & \xi_{\text {inn }}+\left(\xi_{0}+j\right)+\xi_{o}-\min \left(\xi_{\text {inn }},\left(\xi_{0}+j\right)\right) \\
& -\max \left(\left(\xi_{0}+j\right), \xi_{o}\right) \\
\xi_{j-\text { low }}= & \xi_{\text {inn }}+\left(\xi_{0}+j-\varepsilon_{\beta}\right)+\xi_{o} \\
- & \min \left(\xi_{\text {inn }},\left(\xi_{0}+j-\varepsilon_{\beta}\right)\right) \\
& -\max \left(\left(\xi_{0}+j-\varepsilon_{\beta}\right), \xi_{o}\right)
\end{aligned}
$$

where $E_{\alpha}$ and $E_{\gamma}$ are the integer parts of the transverse contact ratio and the total contact ratio, respectively. Fig. 2 presents the typical aspect of function $I_{K}$ according to the sum of the fractional parts of $\varepsilon_{\alpha}$ and $\varepsilon_{\beta},\left(d_{\alpha}+d_{\beta}\right)$, is greater or smaller than 1 .

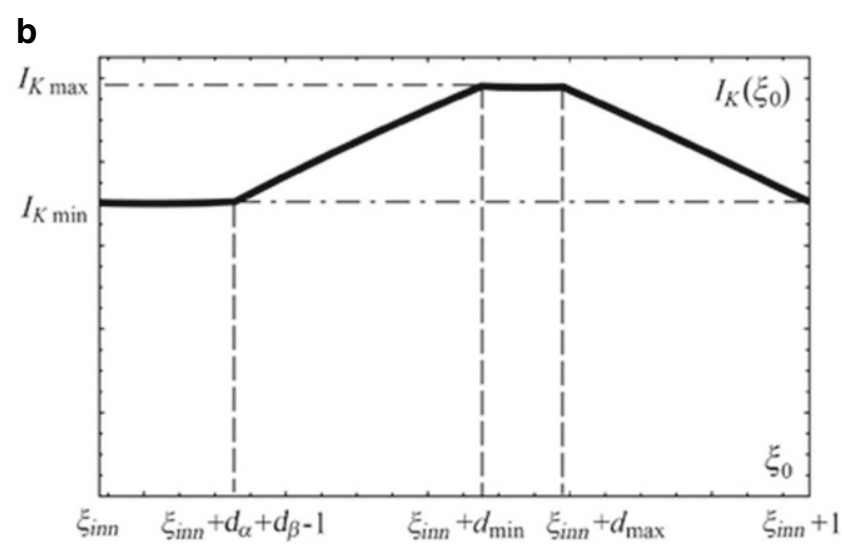

The sliding friction losses corresponding to a small rotation of a point of the line of contact can be expressed as $[8,10,11]$ :

$d^{2} W_{s}=\mu \mathrm{d} F \frac{r_{b 1}}{r_{b 2}}\left(r_{b 2} \pm r_{b 1}\right) \frac{2 \pi}{z_{1}}\left|\frac{2 \pi}{z_{1}} \xi-\tan \alpha_{t}^{\prime}\right| \mathrm{d} \xi_{0}$

in which $\mu$ is the friction coefficient and $\alpha^{\prime}{ }_{t}$ the operating transverse pressure angle. The plus/minus sign corresponds to the external (sun-planet) and internal (planet-ring) gears, respectively. Integrating the losses along the entire line of contact and one complete meshing cycle, the friction losses result in $[8,11]$ :

$$
\begin{aligned}
W_{S} & =F_{T} \frac{r_{b 1}}{r_{b 2}}\left(r_{b 2} \pm r_{b 1}\right) \\
& \times \frac{2 \pi}{z_{1}} \int_{\xi_{\text {inn }}}^{\xi_{\text {inn } 11}} \frac{1}{I_{K}\left(\xi_{0}\right)} \\
& \times\left[\sum_{j=-E_{\alpha}}^{E_{\nu}} \int_{\xi_{0}+j-\varepsilon_{\beta}}^{\xi_{0}+j} \mu \cos b_{0}\left(\xi-\xi_{m}\right)\left|\frac{2 \pi}{z_{1}} \xi-\tan \alpha_{t}^{\prime}\right| \mathrm{d} \xi\right] \mathrm{d} \xi_{0}
\end{aligned}
$$

For the analysis an average friction coefficient according to ISO/TS 6336-21:2017 [21] which accounts velocity, curvature roughness and lubricant properties, will be used. The resulting equation for the friction coefficient, after adjusting the expression in [21] to the load distribution model presented above, is:

$\mu=0.045\left(\frac{\varepsilon_{\beta}}{b V_{\Sigma} \rho_{C}} \frac{\mathrm{d} F}{\mathrm{~d} \xi}\right)^{0.2} \eta_{\mathrm{oil}}^{-0.05} X_{R} X_{L}$

where the sum of velocities $V_{\Sigma}$, the relative curvature radius $\varrho_{C}$, and $\mathrm{d} F / \mathrm{d} \xi$ are all calculated at the pitch point, $\eta_{\text {oil }}$ is the dynamic viscosity of the lubricant, $X_{R}$ the roughness factor, and $X_{L}$ the lubricant factor. 


\section{Analysis of the friction losses}

An analysis of the influence of the output radii of the gears of the planetary gearset on the friction losses will be performed. Since the friction loses are less critical than the teeth strength, the output radii will be chosen in such a manner that the transverse contact ratios of all the gears (the sunplanet gear and the planet-ring gear) will kept constant. In this way, the critical load points will be kept fixed, and the determinant contact and tooth root stresses will remain approximately constant. This means that a single degree of freedom will be available. The planet output radius is chosen as independent variable.

The relative sliding between tooth surfaces is null at the operating pitch point and increase as the contact point moves away from it. The friction losses vary in the same way. Consequently, a good criterion of design will be to ensure the pitch point to be contained in the contact interval. Therefore, considering that the contact point parameter of the operating pitch point is:

$\xi_{P^{\prime}}=\frac{z_{1}}{2 \pi} \sqrt{\frac{1}{\cos ^{2} \alpha_{t}^{\prime}}-1}=\frac{z_{1}}{2 \pi} \tan \alpha_{t}^{\prime}$

Consequently, the interval of the output point parameter of the sun $\xi_{o s}$ for the analysis will be:

$\xi_{P^{\prime}-S P}-\varepsilon_{\alpha-S P} \leq \xi_{o S} \leq \xi_{P^{\prime}-S P}$

Hence forward subscripts $S, P$, and $R$ will denote the sun, the planets, and the ring, respectively, and subscripts $S P$ and $P R$ the sun-planet gear and the planet-ring gear, respectively. To keep the sun-planet gear transverse contact ratio, the output point parameter of the planets should verify:

$\xi_{o S}+\xi_{o P}=\frac{z_{S}+z_{P}}{2 \pi} \tan \alpha_{t-S P}^{\prime}+\varepsilon_{\alpha-S P}$

and therefore:

$\xi_{o P}=\frac{z_{S}+z_{P}}{2 \pi} \tan \alpha_{t-S P}^{\prime}+\varepsilon_{\alpha-S P}-\xi_{o S}$

Similarly, for the planet-ring gear:

$$
\begin{aligned}
\xi_{o R}+\varepsilon_{\alpha-P R} & =\frac{z_{R}-z_{P}}{2 \pi} \tan \alpha_{t-P R}^{\prime}+\xi_{o P} \\
\xi_{o R} & =\frac{z_{R}-z_{P}}{2 \pi} \tan \alpha_{t-P R}^{\prime}-\varepsilon_{\alpha-P R}+\xi_{o P}
\end{aligned}
$$

The output radii of the sun, the planets, and the ring can be obtained from their respective contact parameters, as follows:

$r_{0 i}=r_{b i} \sqrt{1+\left(\frac{2 \pi}{z_{i}} \xi_{o i}\right)^{2}} \quad(i=S, P, R)$

The rack shift coefficients of the sun and the planets will be computed from the output radii, according to a double point of view: (i) to keep the radial clearance, and (ii) to keep the tooth height. To keep the radial clearance, the following condition should be regarded:

$$
\begin{aligned}
C= & r_{o S / o P}+\left(r_{p P / p S}-m h_{\mathrm{aoP} / \mathrm{aoS}}+m x_{P / S}\right) \\
& +m h_{r S / r P}
\end{aligned}
$$

and consequently:

$$
\begin{aligned}
& x_{S}=\frac{1}{m}\left(C-r_{o P}-r_{p S}\right)+\left(h_{\mathrm{aoS}}-h_{r P}\right) \\
& x_{P}=\frac{1}{m}\left(C-r_{o S}-r_{p P}\right)+\left(h_{\mathrm{aoP}}-h_{r S}\right)
\end{aligned}
$$

In Eqs. 22 and $23 C$ is the operating center distance, $r_{p}$ the pitch radius, $h_{a 0}$ the dedendum coefficient, and $h_{r}$ and $h_{r P}$ the initial radial clearance at the sun and planet tooth tip, respectively. These initial radial clearances will not necessarily be equal to de standard ones, given by $m\left(h_{a 0}-h_{a}\right), h_{a}$ being the addendum coefficient, and can be calculated from Eq. 22, for the initial values of $x_{S}$ and $x_{P}$.

To keep the tooth height, the condition to be regarded is:

$r_{o S / o P}=r_{p S / p P}+m x_{S / P}+m h_{a S / a P}-m h_{R S / R P}$

where $h_{R S}$ and $h_{R P}$ are the initial tooth height reduction on sun and planet and can be computed from Eq. 24 for the initial values of $x_{S}$ and $x_{P}$.

The rack shift coefficient of the ring will only be computed from the keeping the tooth height point of view. In this case, the condition to be regarded is:

$r_{o R}=r_{p R}+m x_{R}-m h_{a R}+m h_{R R}$

The analysis will be performed in the following steps:

1. Divide the interval of $\xi_{o S}$ given by Eq. 17 is small subintervals (for example, 1000 subintervals).

2. For each one, compute $x_{S}, x_{P}$, and $x_{R}$ with Eqs. 18-25.

3. Check all the constraints (undercut with vacuum gearing, pointing, root interference, radial clearance, base pitch backlash, and tip interference). 


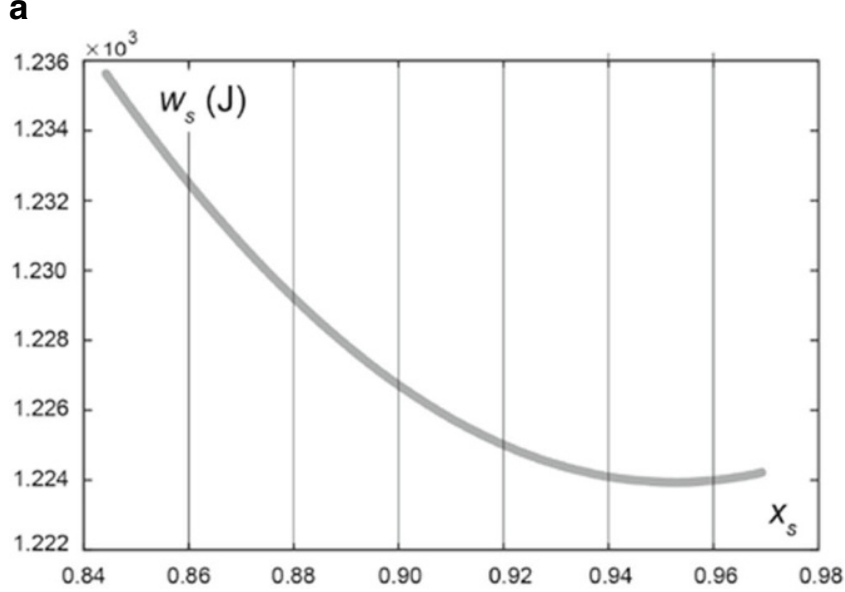

b

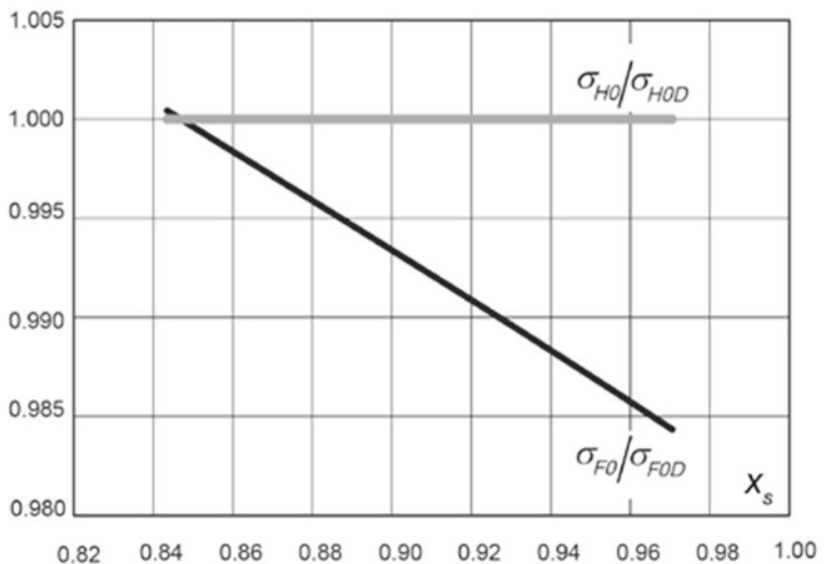

Fig. 3 Evolution of the energy lost (a), and the sun nominal stresses (b), in the first stage, for equal radial clearance

a

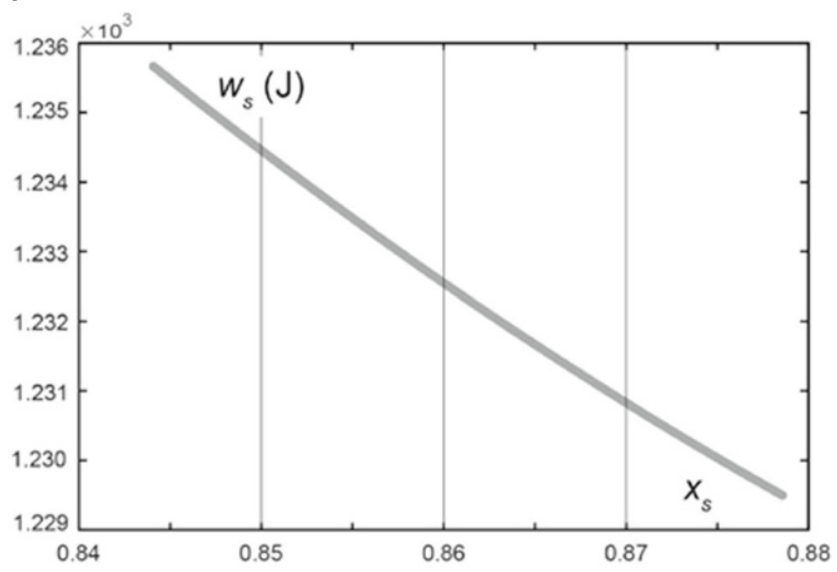

b

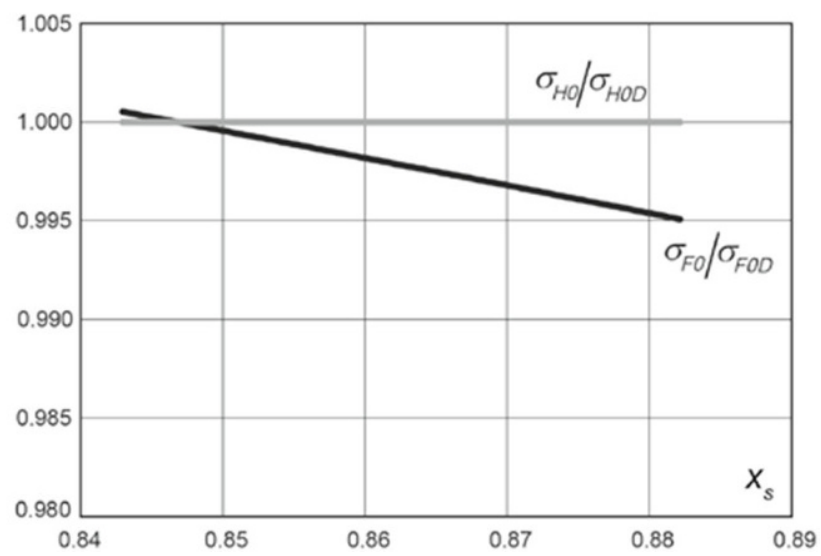

Fig. 4 Evolution of the energy lost (a), and the sun nominal stresses (b), in the first stage, for equal tooth height

4. If all the constraints are regarded, compute the friction losses in both sun-planets and planets-ring gears.

5. Make a graphic representation of the results.

The next section presents the results of this analysis for a multi-MW wind turbine gearbox.

\section{Analysis of a wind turbine gearbox}

The analysis presented in the previous section is being applied to the design of a new multi-MW wind turbine gearbox of Siemens-Gamesa. The gearbox will be made up for three stages: two of them by planetary gears and the output one by helical gears.

\subsection{Analysis of the first stage}

The geometrical pre-analysis of the first planetary stage reveals that, for keeping the radial clearance, the shift coefficient of the sun must be included in the interval $0.8435 \leq x_{S} \leq 0.9706$. For smaller values of $x_{S}$ base pitch interference (negative base pitch backlash) occurs in the planet-ring gear, while for higher values the sun teeth will be pointed.

Fig. 3a shows the variation of the friction losses with the sun shift coefficient. The $y$-axis represents the energy lost along one mesh cycle $\left(\Delta \xi_{0}=1\right)$, in $\mathrm{N} \cdot \mathrm{m}$. It can be observed that the energy losses decrease with $x_{S}$ until reaching a minimum for $x_{S}=0.95$. The correct selection of the sun shift coefficient may reduce the friction losses by $1 \%$.

The goal of this analysis is to improve the friction losses while keeping the stress levels, for which the transverse contact ratio is unmodified. But keeping the location of the determinant contact points do not ensure the same critical 


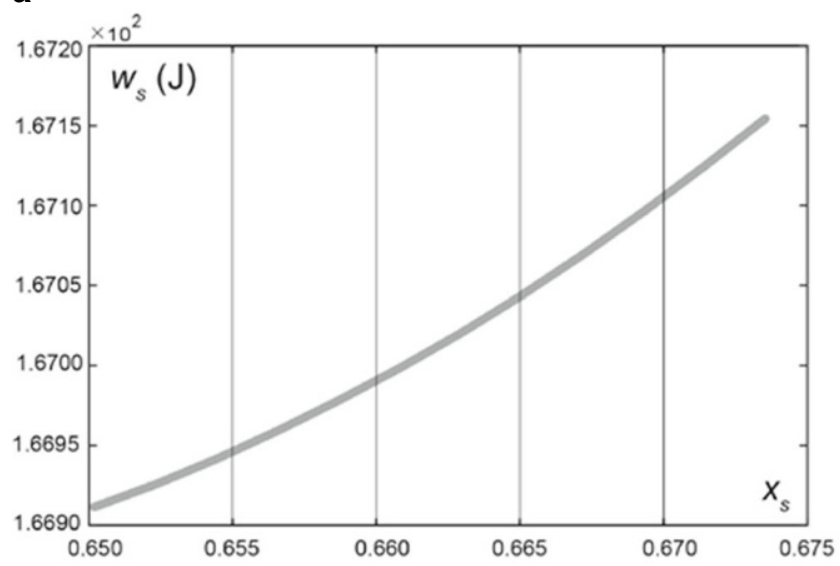

b

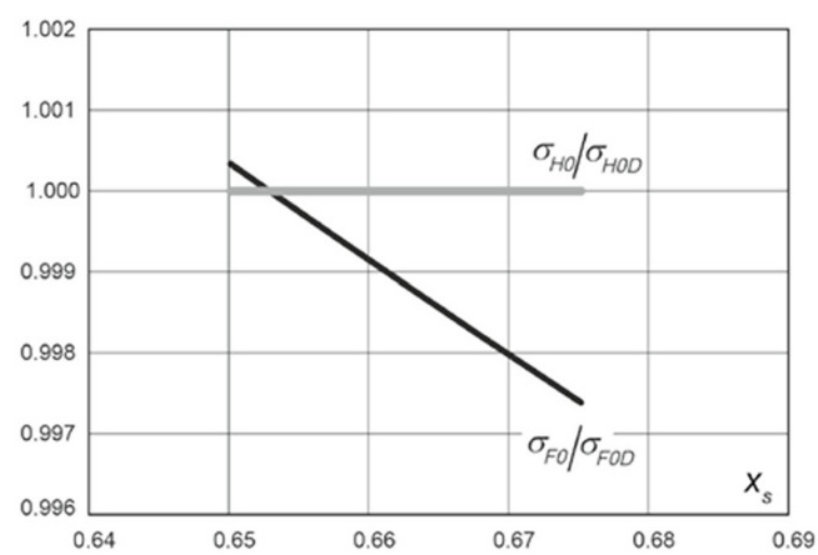

Fig. 5 Evolution of the energy lost (a), and the sun nominal stresses (b), in the second stage, for equal radial clearance

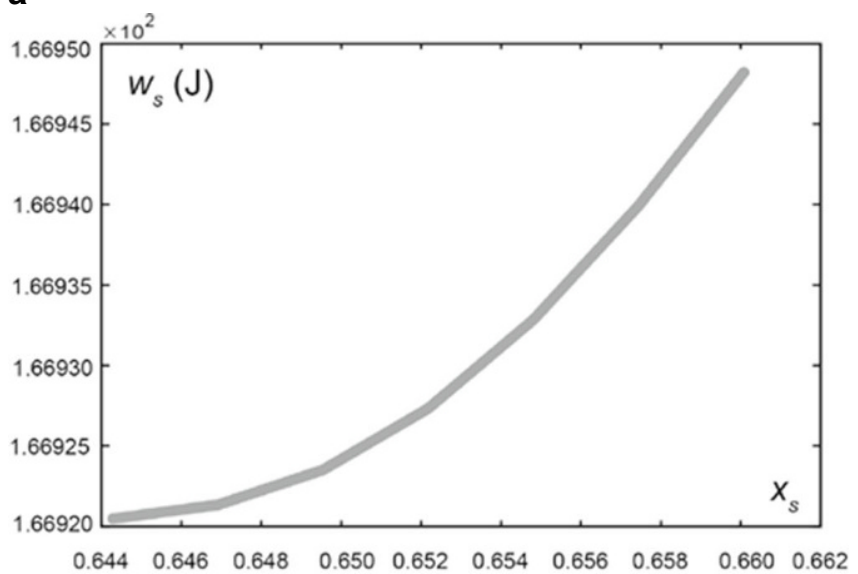

b

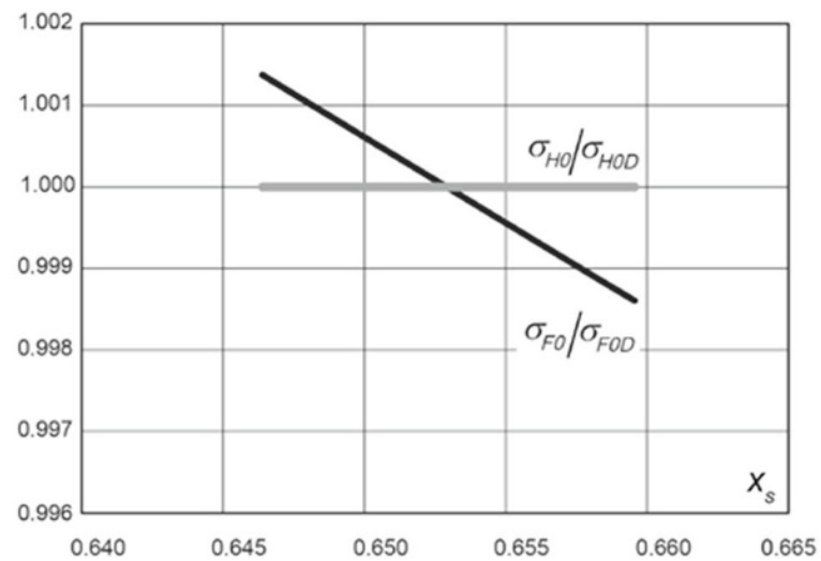

Fig. 6 Evolution of the energy lost (a), and the sun nominal stresses (b), in the second stage, for equal tooth height

stresses, because the tooth geometry is slightly modified, and therefore the stresses should be checked. Fig. $3 \mathrm{~b}$ shows the variation of the nominal contact stress and the nominal tooth-root stress of the sun along the interval of $x_{S}$, according to ISO $6336[22,23] . \sigma_{F 0 D}$ and $\sigma_{H 0 D}$ are preestablished reference stress levels, obtained from the tooth root and pitting stress limits, and the corresponding chosen design factors. It is observed that the variation of the stresses is very small, and the load carrying capacity is kept. Similar curves are obtained for the nominal stresses of the planets and the ring.

For keeping the tooth height, the shift coefficient of the sun must be included in the interval $0.8429 \leq x_{S} \leq 0.8822$. For smaller values of $x_{S}$ base pitch interference occurs in the planet-ring gear, and the same interference for higher values, at the sun-planet gear.

Fig. 4 shows the evolution of the energy lost and the nominal stresses. In this case the energy lost decreases with $x_{S}$, and the friction losses can be reduced by $0.5 \%$. The nominal stresses remain quite uniform.
Although the losses in diagrams in Figs. 3 and 4 are presented as a function of the sun shift coefficient, their values include the friction losses on both the sun-planets and planets-ring contacts.

\subsection{Analysis of the second stage}

For the second stage, for keeping the radial clearance, the shift coefficient of the sun must be included in the interval $0.6502 \leq x_{S} \leq 0.6752$. For smaller values of $x_{S}$ base pitch interference occurs in the planet-ring gear, while for higher values the sun teeth will be pointed.

Fig. 5 shows the evolution of the energy lost and the nominal stresses. The energy lost increases with $x_{S}$, but the fluctuation is very small. In this case, the friction losses cannot be reduced. The nominal stresses are quite uniform again.

For keeping the tooth height, the shift coefficient of the sun must be included in the interval $0.6464 \leq x_{S} \leq 0.6596$. Smaller values of $x_{S}$ produce base pitch interference in the 
Fig. 7 Evolution of the energy lost for equal radial clearance (black line), and for equal tooth height (gray line), in the output stage
Fig. 8 Evolution of the output stage pinion nominal stresses for equal radial clearance (solid line), and for equal tooth height (dashed line)
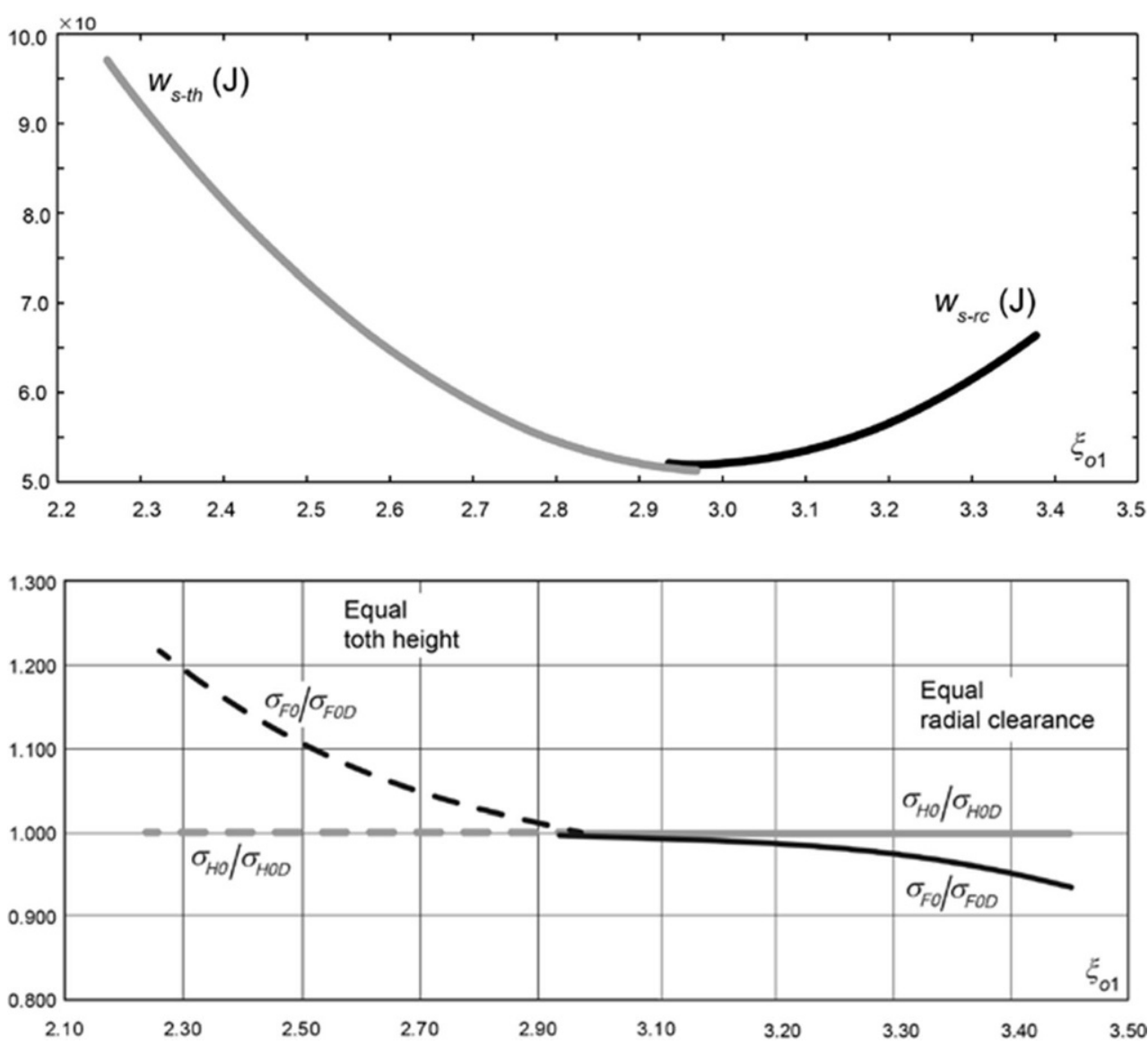

planet-ring gear, and higher values the same interference at the sun-planet gear.

Fig. 6 shows the evolution of the energy lost and the nominal stresses. The energy lost increases with $x_{S}$, though the fluctuation is small again, and the possible reduction of the friction losses would be very small. Once again, the nominal stresses remain uniform.

\subsection{Analysis of the output stage}

The output stage is a single helical gear of 3.5 gear ratio. It can be analyzed in the same way as the sun-planet gears, although the result of the analysis is quite predictable. Friction losses are zero at the operating pitch point and increase as the contact point moves away from it. Consequently, the friction losses will be minimum if the pitch point is placed at the midpoint of the interval of contact. This condition can be expresses as follows:

$\xi_{o 1}=\frac{z_{1}}{2 \pi} \tan \alpha_{t}^{\prime}+\frac{\varepsilon_{\alpha}}{2}$

which in this case results in $\xi_{o 1}=2.99$. Fig. 7 shows the variation of the friction losses with the pinion output point parameter for both approaches of equal radial clearance and equal tooth height. In both diagrams the minimum losses are obtained for the same value of $\xi_{o 1}$ since condition in Eq. 26 is valid for both approaches. However, the shift coefficients to get this value of $\xi_{o 1}$ (and correspondingly $\xi_{o 2}=8.79$ ) are different for each approach:

For equal radial clearance : $\quad x_{1}=0.7048$

For equal tooth height : $\quad x_{1}=0.7104$

In this case, the fluctuation of the friction loses is large, and the correct selection of the shift coefficient may reduce the friction losses by up to $20 \%$ for equal radial clearance, and up to $50 \%$ for equal tooth heigh.

Fig. 8 shows the variation of the ISO nominal tooth root stress and nominal contact stress with the pinion output point parameter for both approaches. In this output stage, the nominal contact stress is very uniform, but the nominal tooth root stress presents non neglectable differences of about $20 \%$ in the case of equal tooth height. This is due 
to the interval of suitable pinion shift coefficient (regarding all the geometrical constraints) is large:

$$
\begin{array}{cc}
\text { For equal radial clearance : } & 0.6587 \leq x_{1} \leq 1.3739 \\
\text { For equal tooth height : } & -0.3814 \leq x_{1} \leq 0.6775
\end{array}
$$

It can be observed in Fig. 7 that for pinion output radii far from the optimum one (namely, $\xi_{o 1}<<2.99$ for equal tooth heigh) the friction losses increase very strongly - up to $100 \%$ higher-and therefore these points have no interest for the analysis. If considered a narrower interval of pinion shift coefficient as $0.2 \leq x_{1} \leq 0.6775$ for equal tooth height, in which the friction losses fluctuate around $20 \%$, the nominal tooth root stress fluctuates around $4 \%$, which is small enough.

In this third stage, the overlap ratio and the transverse contact ratio may have significant influence on the acoustic behavior of the gearbox. However, since the analysis is performed in such a way that the values of both contact ratios remain unchanged, the acoustic behavior is not affected.

\section{Conclusions}

A new optimization method of the friction power losses in wind turbine gearboxes, regarding the design parameters to ensure the preestablished operating conditions, is presented. The dimensions of the gears, as the number of teeth, pressure angle, helix angle, face width, and center distance, are kept. Only variations the output radii are considered in such a manner that the transverse contact ratios do not change, in order to ensure the location of the critical load points for bending and pitting not to change, and therefore the stresses levels and the carrying capacities will to remain more or less unchanged. To adjust the output radii to each analyzed value the rack shift coefficient is chosen according to two different criteria: to keep the initial radial clearance and to keep the tooth height.

The analysis reveals that, for planetary stages, there is an optimal sun shift coefficient for which the curve of friction losses reaches a minimum. Nevertheless, the interval of valid sun shift coefficients is limited by the geometrical constraints (mainly tooth pointing and base pitch interference), and it does not always contain the optimum one. This means that the curve of friction losses may content the minimum, or be increasing continuous, or be decreasing continuous, depending on the specific case. The gearbox analyzed in the paper present different trends for both planetary stages.

Due to the relatively small length of the interval of suitable sun shift coefficients, the reduction of the friction losses on planetary gear stages is not very significant, around $1 \%$. The reduction on single helical stages is higher, up to $50 \%$. Nevertheless, for helical gears the analysis is simpler because the optimal conditions correspond to the pitch point located at the midpoint of the interval of contact.

Funding Spanish Council for Scientific and Technological Research, project PID2019-110996RB-I00 "Simulation and control of transmission error of cylindric gears", School of Engineering of UNED, action 2021-MEC23, "Control of transmission error in cylindric gears with profile modification".

Conflict of interest J.I. Pedrero, D. Martínez-López, J. Calvo-Irisarri, M. Pleguezuelos, M.B. Sánchez and A. Fernández-Sisón declare that they have no competing interests.

Open Access This article is licensed under a Creative Commons Attribution 4.0 International License, which permits use, sharing, adaptation, distribution and reproduction in any medium or format, as long as you give appropriate credit to the original author(s) and the source, provide a link to the Creative Commons licence, and indicate if changes were made. The images or other third party material in this article are included in the article's Creative Commons licence, unless indicated otherwise in a credit line to the material. If material is not included in the article's Creative Commons licence and your intended use is not permitted by statutory regulation or exceeds the permitted use, you will need to obtain permission directly from the copyright holder. To view a copy of this licence, visit http://creativecommons.org/licenses/by/4. $0 /$.

\section{References}

1. Ligata H, Kahraman A, Singh A (2008) An experimental study of the influence of manufacturing errors on the planetary gear stresses and planet load sharing. J Mech Des 130:41701

2. Höhn B-R, Michaelis K (2004) Influence of oil temperature on gear failures. Tribol Int 37:103-109

3. Shen G, Xiang D, Zhu K, Jiang L, Shen Y, Li Y (2018) Fatigue failure mechanism of planetary gear train for wind turbine gearbox. Eng Fail Anal 87:96-110

4. Xu H, Kahraman A, Anderson N, Maddock D (2007) Prediction of mechanical efficiency of parallel-axis gear pairs. J Mech Des 129:58-68

5. Seetharaman S, Kahraman A (2009) Load-independent spin power losses of a spur gear pair: model formulation. J Tribol 131:22201

6. Seetharaman S, Kahraman A (2010) A windage power loss model for spur gear pairs. Tribol Trans 53:473-484

7. Li S, Kahraman A (2010) A transient mixed elastohydrodynamic lubrication model for spur gear pairs. J Tribol 132:11501

8. Pleguezuelos M, Pedrero JI, Sánchez MB (2010) Simplified calculation method for the efficiency of involute helical gears. In: New trends in mechanism science, pp 217-224

9. Baglioni S, Cianetti F, Landi L (2012) Influence of the addendum modification on spur gear efficiency. Mech Mach Theory 49:216-233

10. Pleguezuelos M, Pedrero JI, Sánchez MB (2013) Analytical expressions of the efficiency of standard and high contact ratio involute spur gears. Math Probl Eng 2013:1-14

11. Nutakor C, Klodowsky A, Sopanen J, Mikkola A, Pedrero JI (2017) Planetary gear sets power loss modeling: application to wind turbines. Tribol Int 105:42-54

12. Castillo JM (2002) The analytical expression of the efficiency of planetary gear trains. Mech Mach Theory 37:197-214

13. Talbot DC, Kahraman A, Singh A (2012) An experimental investigation of the efficiency of planetary gear sets. J Mech Des $134: 21003$ 
14. Kahraman A, Hilty DR, Singh A (2015) An experimental investigation of spin power losses of a planetary gear set. Mech Mach Theory 86:48-61

15. Jianying L, Quingchun H (2016) Power analysis and efficiency calculation of the complex and closed planetary gears transmission. Energy Procedia 100:423-433

16. Pedrero JI, Pleguezuelos M, Artés M, Antona JA (2010) Load distribution model along the line of contact for involute external gears. Mech Mach Theory 45:780-794

17. Sánchez MB, Pleguezuelos M, Pedrero JI (2013) Enhanced model of load distribution along the line of contact for non-standard involute external gears. Meccanica 48:527-543

18. Sánchez MB, Pleguezuelos M, Pedrero JI (2017) Approximate equations for the meshing stiffness and the load sharing ratio of spur gears including hertzian effects. Mech Mach Theory 109:231-249
19. Sánchez MB, Pleguezuelos M, Pedrero JI (2016) Calculation of tooth bending strength and surface durability of internal spur gear drives. Mech Mach Theory 95:102-113

20. Sánchez MB, Pleguezuelos M, Pedrero JI (2019) Strength model for bending and pitting calculations of internal spur gears. Mech Mach Theory 133:691-705

21. ISO/TS 6336-21:2017 (2017) Calculation of load capacity of spur and helical gears-Part 21: Calculation of scuffing load capacity (also applicable to bevel and hypoid gears) - Integral temperature method. International Organization for Standardization, Geneva, pp $1-49$

22. ISO 6336-2:2019 (2019) Calculation of load capacity of spur and helical gears-Part 2: Calculation of surface durability (pitting). International Organization for Standardization, Geneva, pp 1-37

23. ISO 6336-3:2019 (2019) Calculation of load capacity of spur and helical gears-Part 3: Calculation of tooth bending strength. International Organization for Standardization, Geneva, pp 1-55 